\title{
HACIA LA UNIVERSALIZACIÓN DE LA SEGURIDAD SOCIAL EN MÉXICO: ANÁLISIS JURÍDICO DE LA PROBLEMÁTICA QUE GENERA LA DUPLICIDAD EN EL ASEGURAMIENTO
}

TOWARDS A UNIVERSAL SOCIAL SECURITY IN MEXICO: LEGAL ANALYSIS ON THE INSURANCE DUPLICITY GENERATED PROBLEM ${ }^{1}$

Jessica Guadalupe GonzÁlez Posadas ${ }^{2}$

RESUMEN: En nuestro país, la seguridad social es concebida como un derecho obrero, garantizado por el artículo 123 de la Constitución Política de los Estados Unidos Mexicanos, en la fracción XXIX del apartado A y las fracciones XI y XIII del apartado B; situación que per sé genera una delimitación de su cobertura -así como de su financiamiento-, constrinéndose a la población económicamente activa. En consecuencia, el sistema de seguridad social mexicano se ha manifestado, desde su concepción, como un régimen limitado -debido a la falta de universalidad en su cobertura- y fragmentado -ante la multiplicidad de instituciones primariamente responsables de la prestación de los servicios públicos correspondientes- que, a últimas fechas, puede calificarse además como desfinanciado, por la escases de reservas suficientes para garantizar su sustentabilidad. Tales vicios primigenios han propiciado una duplicidad en el aseguramiento -entendida ésta como la doble o hasta triple cobertura de un mismo individuo respecto de las diversas instituciones que prestan estos servicios de solidaridad social-, así como una inadecuada interpretación y aplicación de las legislaciones existentes en materia de seguridad social por los operadores jurídicos; causando un detrimento directo de las finanzas que soportan nuestro tambaleante sistema de seguridad social.

PAlabras Clave: Seguridad social, universalidad, unidad, solidaridad, duplicidad en el aseguramiento, financiamiento, régimen obligatorio, pensiones.

${ }^{1}$ Trad. Jennifer C. González Posadas.

${ }^{2}$ Maestra en Derecho por el Programa de Posgrado en Derecho de la UNAM. Abogado Procurador del Instituto Mexicano del Seguro Social, Delegación Estatal Aguascalientes. 
ABstract: In Mexico, social security is conceived as a working right guaranteed by the Mexican Constitution article 23, fraction XXIX, section "A" and fractions XI and XIII, section "B". This situation itself delimits it's coverage -as well as it's funding- that constrains to economically active population. In consequence, mexican social security system has emerge, from its conception, as a limited regime due to its lack of universal coverage, and fragmented because of the multiplicity of institutions primarily responsible of the corresponding public services, which lately can also qualify as unfunded in the absence of sufficient reserves its guarantee its sustainability. Such original vices have promoted an insurance duplicity -understood as the double or even triple coverage of the same individual by the different institutions that give this social solidarity services-, as well as an inadequate interpretation and application of the various social security laws by the legal operators, causing a direct detriment to the finances that support our wobbly social security system.

KEYWORDS: Social security, universal coverage, unity, solidarity, insurance duplicity, financing, obligatory regime, social security payments.

SUMARIO: I. Introducción; II. Desarrollo histórico de la seguridad social; III. La seguridad social como un derecho fundamental; IV. Duplicidad en el aseguramiento y el problema del financiamiento; V. Propuesta de solución: el retorno al Plan Beveridge y la creación de un sistema único de pensiones; VI. Fuentes.

\section{INTRODUCCIÓN}

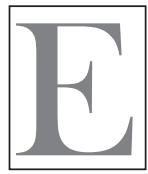

l objeto del presente trabajo es el sistema de seguridad social garantizado por el artículo 123 de la Constitución Política de los Estados Unidos Mexicanos, entendido no sólo como una de las principales prerrogativas concebidas en favor de la clase obrera, sino también como el derecho social por excelencia, tendente a proteger a la persona humana como integrante de un grupo social.

La Organización Internacional del Trabajo (OIT) ha definido a la seguridad social como

La protección que la sociedad proporciona a sus miembros, mediante una serie de medidas públicas, contra las privaciones económicas y sociales que de otra manera derivarían de la desaparición o de una fuerte 
reducción de sus ingresos, como consecuencia de enfermedad, maternidad, accidente de trabajo o enfermedad profesional; desempleo, invalidez, vejez y muerte, y también la protección en forma de asistencia médica y de ayuda a las familias con hijos ${ }^{3}$.

Así, la seguridad social es comúnmente explicada como "el conjunto de mecanismos para la cobertura de contingencias sociales de todos los habitantes del país y, específicamente, del trabajador y su familia" ${ }^{4}$. Concepto que denota, en un primer momento, una intención de universalidad en la atención de los requerimientos del grueso de la población; esto es, que dicha protección no sea privativa de la clase obrera, sino que también alcance a los diversos sectores sociales, sin la exigencia de un trabajo remunerado. En palabras de Ávila Salcedo, "la universalidad como distintivo de la seguridad social implica protección a la persona física por el sólo hecho de serlo, es un derecho a su favor que justifica acciones continuadas para ampliar su cobertura" ${ }^{5}$.

No obstante, si bien la fracción XXIX del apartado A del artículo 123 constitucional parece corresponder a tal propósito al declarar de utilidad pública la Ley del Seguro Social e instaurar un sistema de seguros encaminados a la protección y bienestar de los trabajadores, campesinos, no asalariados y otros sectores sociales y sus familias, lo cierto es que dicho objetivo pierde claridad e incluso se desvanece al especificar, en las fracciones XI y XIII del apartado B del citado precepto, las bases para la organización de la seguridad social correspondiente a los trabajadores al servicio del Estado y los miembros en activo del Ejército, Fuerza Aérea y Armada; excluyéndolos del resto de la población que se encuentra -en teoría- amparada por la Ley del Seguro Social, y sujetándolos a un régimen de protección y

\footnotetext{
${ }^{3}$ Ibidem, p. 17.

${ }^{4}$ Capón Filas, Rodolfo y Giorlandini, Eduardo, Diccionario de Derecho Social. Derecho del trabajo y la seguridad social, 1a. ed., Argentina, Rubinzal y Culzoni Editores, 1987, p. 455, consultado en https://archivos.juridicas.unam.mx/wrwr/bjo/libros/3/1412/10.pdf, el 08 de agosto de 2018.

${ }^{5}$ Ávila Salcedo, Luis F., La seguridad social y el Instituto Mexicano del Seguro Social, 1a. ed., México, Editorial Porrúa, 2007, p. 28.
} 
asistencia sociales precisamente organizado en atención a su calidad de trabajadores, a grado tal que la Ley del Instituto de Seguridad y Servicios Sociales de los Trabajadores del Estado no utiliza la palabra "asegurado", sino la de "trabajador"

Asimismo, de una interpretación sistemática de los artículos 12, 13 y 14 de la Ley del Seguro Social se advierte que la protección más amplia, integral y completa que dicha legislación prevé es proporcionada, de manera exclusiva y obligatoria, a las personas que de conformidad con los artículos 20 y 21 de la Ley Federal del Trabajo prestan, en forma permanente o eventual, un servicio remunerado, personal y subordinado; a los socios de las sociedades cooperativas y a las personas que determine el Ejecutivo Federal a través del Decreto respectivo. En tanto que los campesinos, no asalariados y demás sectores sociales a que hace referencia la fracción XXIX del artículo 123 constitucional, sólo podrán acceder voluntariamente a las prestaciones que el régimen obligatorio del seguro social otorga, mediante convenio con el Instituto Mexicano del Seguro Social en el que se especifiquen, entre otros términos, la vigencia de la prestación de los servicios de seguridad social; las prestaciones a otorgar; las cuotas a cargo de los asegurados y demás sujetos obligados, y la contribución del Gobierno Federal, únicamente cuando en su caso proceda ésta.

De las anteriores consideraciones es fácil advertir, pues, que en nuestro país y a pesar de las disposiciones constitucionales, la seguridad social se ha desarrollado exclusivamente "a través de instituciones... encargadas de proporcionar una serie de seguros sociales a la población que se encuentra bajo una relación de trabajo formal; es decir, que prestan un trabajo personal y subordinado y cotizan en el IMSS, ISSSTE o en las fuerzas armadas"7. De manera tal que para acceder a las prestaciones en especie y en dinero que prevé la Ley del Seguro Social, el resto de la población debe incorporarse voluntariamente a través del pago de una cuota anual.

\footnotetext{
${ }^{6}$ López Ruíz, Miguel (editor), Diccionario jurídico sobre seguridad social, 1a. ed., México, ISSSTE - IMSS - UNAM, Instituto de Investigaciones Jurídicas, 1994, p. 54, consultado en https://archivos.juridicas.unam.mx/wrw/bjo/libros/2/736/4.pdf, el 08 de agosto de 2018.

${ }^{7}$ Sánchez - Castañeda, Alfredo, op.cit., nota 1, p. 3.
} 
Desde su concepción, el sistema de seguridad social mexicano se ha manifestado como un régimen limitado, debido a la falta de universalidad en su cobertura, y fragmentado, ante la multiplicidad de instituciones primariamente responsables de la prestación de los servicios públicos correspondientes. Vicios primigenios que han derivado en una tercera deficiencia: la duplicidad en el aseguramiento, entendida como la doble o hasta triple cobertura de un mismo individuo respecto de las diversas instituciones encargadas de la administración y organización de la seguridad social.

Según Sánchez - Castañeda, "uno de los grandes problemas de la seguridad social mexicana tiene que ver con la ausencia de unidad en la administración y gestión de la seguridad social”. Así, conforme al artículo 123 constitucional, son tres las instituciones consagradas a la seguridad social: el Instituto Mexicano del Seguro Social (IMSS), el Instituto de Seguridad y Servicios Sociales de los Trabajadores del Estado (ISSSTE) y el Instituto de Seguridad Social para las Fuerzas Armadas Mexicanas (ISSFAM); organismos públicos descentralizados que además de contar con personalidad jurídica y patrimonio propios, disponen también de una ley reglamentaria que contiene y regula las prestaciones correspondientes a cada régimen de seguridad social.

Dichas legislaciones prevén múltiples y muy diversas prestaciones para tres grupos sociales disímiles entre sí: los trabajadores protegidos por el apartado A del artículo 123 constitucional y campesinos, no asalariados y otros sectores sociales y sus familias, en tratándose de la Ley del Seguro Social; los trabajadores al servicio del Estado, por lo que respecta a la Ley del ISSSTE, y los miembros del Ejército, de la Fuerza Aérea y de la Armada de México, en activo o en situación de retiro, y sus familiares en línea directa, por cuanto hace

\footnotetext{
${ }^{8}$ Sánchez - Castañeda, Alfredo, "La reformulación de los paradigmas: la reforma a la seguridad social y la creación del Instituto Mexicano de Protección Social”, en Mendizábal Bermúdez, Gabriela et. al. (coord.), Condiciones de Trabajo y Seguridad Social, 1a. ed., México, UNAM, Instituto de Investigaciones Jurídicas, consultado en 2012, p. 23, https://archivos.juridicas.unam.mx/wwr/bjv/libros/7/3142/2.pdf, el 12 de agosto de 2018.
} 
a la Ley del Instituto de Seguridad Social para las Fuerzas Armadas Mexicanas. Sin embargo, ninguna norma o disposición impide que un mismo individuo sea sujeto de la protección de dos o más regímenes de seguridad social a la vez y que, como tal, tenga acceso de manera conjunta a las prestaciones -en dinero y en especie- propias de cada uno de éstos.

Situación que, en contraste con la falta de universalidad, provoca que el individuo que ha cotizado para dos o más instituciones de seguridad social -verbi gratia, para ISSSTE e IMSS- pueda disfrutar, simultáneamente, de dos o más pensiones, en detrimento de las finanzas que soportan el tambaleante sistema de seguridad social. Esto es, nada impide que aquel trabajador al servicio del Estado, que también cotizó en el régimen obligatorio del seguro social (IMSS), disfrute a la par de una pensión por riesgo de trabajo, en términos de la fracción II del artículo 62 de la Ley del ISSSTE y de una pensión de invalidez, conforme a los artículos 119 y 120, fracción II, de la vigente Ley del Seguro Social; pudiendo, además, obtener una tercera pensión, ahora por viudez o por causa de muerte, en atención a su calidad de beneficiario o causahabiente, según lo dispuesto por los artículos 64, fracción II, y 127, fracción I, de esta última legislación, o los diversos artículos 67, 68, fracción I, y 129 de aquella.

Debiendo entender por pensión, en términos generales, "la prestación económica (en dinero) otorgada, periódicamente (mes con mes), por una institución de seguridad social a una persona física asegurada o a sus causahabientes, al reunir los requisitos señalados por la legislación correspondiente" ${ }^{9}$.

\section{DESARROLLO HISTÓRICO DE LA SEGURIDAD SOCIAL}

Los ideales de libertad e igualdad que sirvieron de estandarte a la Revolución Francesa y que, a la postre, dieron contenido al liberalismo y al individualismo que caracterizaron al Estado del siglo XIX,

\footnotetext{
${ }^{9}$ López Ruíz, Miguel (editor), op. cit., nota 5, p. 323.
} 
generaron una profunda desigualdad social en perjuicio de las clases más desposeídas. Y si bien el artículo 21 de la Constitución franca de 1793 estableció por primera vez la obligación social de proporcionar a aquellos caídos en desgracia los medios mínimos de subsistencia y concibió, asimismo, a la ayuda social como un deber sagrado ${ }^{10}$, en la realidad dicho precepto fue sólo letra muerta.

Hombres, mujeres y niños trabajaban por igual durante infatigables jornadas, en las más inmundas condiciones y a cambio de exiguos salarios, sin estabilidad en el empleo ni prestaciones adicionales a tan irrisorio estipendio. $\mathrm{Al}$ respecto, el maestro De la Cueva tiene a bien señalar:

... la libertad de contratación no existió nunca, porque el trabajador apremiado por la miseria tenía que someterse a la voluntad del patrono, quien si podía esperar que viniera otra persona a solicitar el empleo; y usó del poder de su voluntad con sentido autoritario y con refinada crueldad: se valió del trabajo de los niños, estableció jornadas de catorce o más horas y fijó como salario la cantidad de dinero estrictamente indispensable para la subsistencia del obrero en una vida más animal que humana; y como si no fuera suficiente, mantenía al trabajador en la angustia del mañana con la espada del despido libre ${ }^{11}$.

La rebeldía contra la injusticia social se propagó de manera paulatina a cada fábrica y taller de Europa occidental y, más tarde, de América Latina; y, finalmente, el proletariado hubo de echar mano de los diversos medios lícitos -manifestaciones públicas- e ilícitos -la asociación sindical no autorizada- de que disponía, a fin de luchar por condiciones más humanas para la prestación de los servicios ${ }^{12}$.

La miserable situación de la clase trabajadora en Francia e Inglaterra y la influencia que sobre ésta ejerció el marxismo, fueron los principales detonantes de varias revoluciones durante gran parte del

\footnotetext{
${ }^{10}$ Cázares García, Gustavo, Derecho de la seguridad social. Historia, doctrina y jurisprudencia, 3a. ed., México, Editorial Porrúa, 2014, p. 13.

${ }^{11}$ De la Cueva, Mario, El nuevo derecho mexicano del trabajo, 7a. ed., t. II, México, Editorial Porrúa, 1981, p. 10.

${ }^{12}$ Ibidem, p. 13.
} 
siglo XIX, como la llamada Primavera de los Pueblos de 1848, las cuales culminaron con la creación de normas protectoras para los trabajadores frente a los abusos del capital ${ }^{13}$. Cruzadas que, en su conjunto y sin importar la latitud en que se gestaron, enarbolaron como reclamos fundamentales: la libertad sindical, la de negociación y contratación colectivas y la de huelga; un derecho individual del trabajo que propiciara un mínimo de justicia social; y una previsión social que defendiera a los hombres contra los infortunios del trabajo $^{14}$.

Una de las primeras conquistas del movimiento obrero aconteció en Alemania de la mano de Otto von Bismarck, quien entre 1883 y 1889 instituyó un sistema de seguros sociales de protección obligatoria, sujetos a la condición de trabajador y de cuyo financiamiento es éste corresponsable, junto con el empleador. Según Bismarck, “del trabajador importa no solamente su presente, sino y acaso más aun, su futuro, y era así, porque en el presente le salva su esfuerzo, en tanto que el futuro es lo imprevisto y desconocido, y por ello debe asegurarse" ${ }^{15}$; pensamiento que lo llevó a concebir uno de los grandes sistemas de seguridad social, basado en una relación bilateral: a cambio de una contribución aportada por el asegurado, le era acordada una indemnización en caso de sufrir alguno de los riesgos cubiertos ${ }^{16}$.

Sin embargo, tal regulación alemana en realidad obedeció al tenaz intento del canciller por contrarrestar el avance del socialismo y acallar las voces que exigían mejores condiciones laborales; intención que Bismarck expresó señalando que: "Un hombre que tiene asegurado su porvenir, su vejez tranquila, el bienestar de sus familiares, no es un anarquista ni atenta contra la vida del emperador; démosle ahora a los pobres aquello a lo que tienen derecho antes de que nos lo arrebaten por la fuerza"17.

\footnotetext{
${ }^{13}$ Burgoa, Ignacio, Las garantías indiwiduales, 41a. ed., México, Editorial Porrúa, 2009, p. 698.

${ }^{14}$ De la Cueva, Mario, op. cit., nota 10, p. 13.

${ }^{15}$ Cázares García, Gustavo, op. cit., nota 9, p. 17.

${ }^{16}$ Sánchez - Castañeda, Alfredo, op. cit., nota 1, p. 8.

${ }^{17}$ Cázares García, Gustavo, op. cit., nota 9.
} 
Por lo que sería hasta 1919, con la Constitución de Weimar, que los principios y normas del derecho del trabajo fueron reconocidos en el continente europeo como derechos fundamentales del hombre; destacando, en lo que a nuestro tema interesa, que "la seguridad social partió de la protección a la maternidad y de la educación y preparación del niño, para llegar a la preservación de la salud y de la vida y a la ayuda al hombre y a su familia cuando los riesgos de la actividad y de la vida provocan la imposibilidad de trabajar" ${ }^{18}$.

También en la América Latina el germen de la revolución social había echado sus raíces, siendo la Constitución Política de los Estados Unidos Mexicanos, promulgada el 05 de febrero de 1917, la primera ley fundamental que consagró los derechos al trabajo digno y a la seguridad social; estableciendo, en la fracción XXIX del artículo 123, la utilidad social de las cajas de seguros populares, de invalidez, de vida, de cesación involuntaria de trabajo, de accidentes y otros con fines análogos, así como la obligación del gobierno -federal y estatal- de fomentar la organización de tales instituciones, con el objeto de infundir e inculcar la previsión popular ${ }^{19}$. Disposición que sería modificada, mediante reforma impulsada por el Presidente interino Emilio Portes Gil y publicada en el Diario Oficial de la Federación del 06 de septiembre de 1929, a fin de declarar de utilidad pública la expedición de la Ley del Seguro Social; enmienda a razón de la cual se confirió al Congreso de la Unión la facultad de legislar en materia de trabajo ${ }^{20}$.

En 1919 fue creada la Organización Internacional del Trabajo (OIT), como parte del Tratado de Versalles que terminó con la Primera Guerra Mundial2 ${ }^{21}$; agencia de las Naciones Unidas cuya asamblea es la encargada de aprobar las convenciones internacionales

\footnotetext{
${ }^{18}$ De la Cueva, Mario, op. cit., nota 10, p. 21.

${ }^{19}$ Constitución Política de los Estados Unidos Mexicanos, que reforma la de 5 de febrero de 1857, consultado en https://wrerr.scjn.gob.mx/sites/default/files/cpeum/documento/2017-03/CPEUM-123.pdf, el 10 de agosto de 2018.

${ }^{20}$ Cázares García, Gustavo, op. cit., nota 9, pp. 61, 62.

${ }^{21}$ Organización Internacional del Trabajo, consultado en http://wwwe.ilo.org/global/ about-the-ilo/history/lang--es/index.htm, el 10 de agosto de 2018.
} 
sobre la materia y que estableció, en su décimo séptima reunión de 1933, la obligación a cargo del patrón de instituir seguros que protegieran a sus trabajadores contra las contingencias provocadas por la vejez, la invalidez y la muerte, "consistentes en el pago de prestaciones periódicas que constituyeron lo que en términos comunes se ha denominado pensión”22. Y para 1944, la Declaración de Filadelfia de la OIT reafirmó la necesidad de una cobertura universal de la seguridad social como instrumento internacional para la prosecución del bienestar material y pleno desarrollo espiritual del ser humano ${ }^{23}$.

En 1942, el gobierno inglés lanza un plan de seguridad social llamado Social Insurance and Allied Service, encomendado a sir William Beveridge; con el cual se estableció el modelo contributivo de la seguridad social, esto es, su financiamiento a través de impuestos y contribuciones fijas. Dicho proyecto se basó en los principios de universalidad y solidaridad, de manera que asegura a todos los ciudadanos ingleses servicios médicos, una pensión por vejez y gastos de entierro, a cambio de una contribución única semanal ${ }^{24}$. El Plan de Seguridad Social implementado en Inglaterra, se refiere a la seguridad social con el objeto de

significar la consecución de un ingreso destinado a reemplazar las entradas, cuando éstas dejan de percibirse, sea por desocupación, por enfermedad o por accidente; a prevenir el retiro por edad y la pérdida del sustento, causada por muerte de otras personas; y a (sic) hacer frente a gastos extraordinarios, como los relacionados con nacimiento, muerte, o casamiento. Originalmente "seguridad social" significa seguridad de ingresos hasta un mínimo, pero la previsión de ingresos debiera estar asociada con medidas destinadas a terminar, a la brevedad posible, con la interrupción de entradas ${ }^{25}$.

En tanto que, en América Latina, sería Venezuela el adalid de la seguridad social, promoviendo la primera ley del seguro social en

${ }^{22}$ López Ruíz, Miguel (editor), op. cit., nota 5, p. 324.

${ }^{23}$ Sánchez - Castañeda, Alfredo, op.cit., nota 2.

${ }^{24}$ Ibidem, pp. 9 - 13.

${ }^{25}$ Ibidem, p. 11. 
1940; adelantándose a México, que el 19 de enero de 1943 publicaría la Ley del Seguro Social como instrumento para proteger el salario de las contingencias que pudieran aminorarlo ${ }^{26}$; advirtiéndose que, desde su concepción, la cobertura del sistema de seguridad social mexicano se restringe a los trabajadores asalariados, "ampliándose" en favor de los no asalariados y demás sectores sociales, a través de la incorporación voluntaria.

El 10 de diciembre de 1948, la Asamblea General de las Naciones Unidas proclamó la Declaración Universal de Derechos Humanos como "ideal común por el que todos los pueblos y naciones deben esforzarse" ${ }^{27}$; documento que en su artículo 22 reconoce el derecho a la seguridad social como uno de los derechos humanos fundamentales.

En 1959, el artículo 123 de la Constitución Política de los Estados Unidos Mexicanos sería reformado para establecer un régimen de seguridad social diverso para los trabajadores al servicio del gobierno federal; publicándose el 20 de noviembre de 1959, en consecuencia, la primera Ley del Instituto de Seguridad y Servicios Sociales de los Trabajadores del Estado. Y, finalmente, en 1976 entraría en vigor la Ley del Instituto de Seguridad Social para las Fuerzas Armadas Mexicanas, abrogando el resto de disposiciones que sobre la materia se habían expedido ${ }^{28}$.

El 3 de enero de 1976 entra en vigor el Pacto Internacional de Derechos Económicos, Sociales y Culturales que, en su artículo $2^{\circ}$, impone a los Estados Partes la obligación de adoptar, hasta el máximo de los recursos que dispongan, las medidas necesarias para lograr la plena efectividad de los derechos que el mismo reconoce, entre los que se encuentra el derecho de toda persona a la seguridad social $^{29}$. Siendo hasta el 17 de noviembre de 1988 que la Convención

\footnotetext{
${ }^{26}$ Cázares García, Gustavo, op. cit., nota 9, p. 68.

${ }^{27}$ Declaración Universal de Derechos Humanos, consultado en https://wrere.ohchrorg/EN/ UDHR/Documents/UDHR_Translations/spn.pdf, el 15 de agosto de 2018.

${ }^{28}$ Sánchez - Castañeda, Alfredo, op.cit., nota 1, pp. 34 y 39.

${ }^{29}$ Pacto Internacional de Derechos Económicos, Sociales y Culturales, consultado en https://
} 
Americana sobre Derechos Humanos fue adicionada en materia de derechos económicos, sociales y culturales mediante el llamado Protocolo de San Salvador; instrumento internacional que reafirma los derechos reconocidos en el Pacto Internacional de Derechos Económicos, Sociales y Culturales, así como los compromisos adquiridos por los Estados Partes de éste ${ }^{30}$.

\section{LA SEGURIDAD SOCIAL COMO DERECHO FUNDA-}

\section{MENTAL}

De los antecedentes históricos narrados en párrafos que anteceden, destaca el constante requerimiento al Estado, por parte del proletariado y demás clases sociales en desventaja, de mejores condiciones jurídicas, económicas y sociales para el desarrollo de una vida digna. Es así que, a partir de la inclusión en la Constitución Política de los Estados Unidos Mexicanos de 1917 de las llamadas garantías sociales, el orden jurídico nacional ha clasificado el derecho de la seguridad social como un derecho eminentemente social, de manera conjunta con el derecho del trabajo y el derecho agrario ${ }^{31}$, en tanto que bajo dicha clasificación se engloba a aquellos derechos que "se caracterizan por constituir prerrogativas o pretensiones que los ciudadanos, individual o colectivamente, pueden esgrimir frente a la actividad social y jurídica del Estado, es decir, que implican el poder de exigir a éste determinadas prestaciones positivas" ${ }^{32}$. Concepto que, por definición, denota el reconocimiento de tales derechos en favor del ser humano, pero desde su condición como integrante de un determinado grupo social.

wrwe.ohchr.org/sp/professionalinterest/pages/cescr.aspx, el 15 de agosto de 2018.

${ }^{30}$ Protocolo adicional a la Convención Americana sobre Derechos Humanos en materia de derechos económicos, sociales y culturales "Protocolo de San Salvador", consultado en http://legislacion. scjn.gob.mx/Buscador/Paginas/wfOrdenamientoDetalle.aspx? $q=$ PlOrqrSvLTzAsquzQ7fUky 4kZb76bUIVN1 T2hXjH6GTCSSSNoFe TrwOgvEINJjM8, el 15 de agosto de 2018.

${ }^{31}$ De la Cueva, Mario, op.cit., nota 10, p.76.

${ }^{32}$ Rodríguez y Rodríguez, Jesús, "Derechos Sociales”, Diccionario furídico Mexicano, 1a. ed., México, UNAM, Instituto de Investigaciones Jurídicas, 1983, t. III, p. 228, https://archivos.juridicas.unam.mx/wrww/bjo/libros/3/1170/9.pdf. 
Sin embargo, como señala el maestro Carpizo, "todos los derechos humanos forman una unidad y se imbrican entre sí... [de manera que clasificarlos] resulta provechoso para quien se aproxima a ellos para contemplar un panorama general de los mismos y, tal vez, auxilie a su comprensión" 33 . Por tanto, catalogar el derecho a la seguridad social como un derecho social, no implica negar su carácter de derecho humano fundamental. Basta considerar que, por definición, la seguridad social implica necesariamente el principio de universalidad, esto es, que dicha protección comprenda a toda la población y, por tanto, corresponda a la persona humana en general y no sólo en atención a su condición marginal o de desventaja.

Intensión a la que corresponde el artículo 22 de la Declaración Universal de Derechos Humanos, proclamada en París en 1948 por la Asamblea General de las Naciones Unidas y que a la letra refiere

Toda persona, como miembro de la sociedad, tiene derecho a la seguridad social y a obtener, mediante el esfuerzo nacional y la cooperación internacional, habida cuenta de la organización y recursos de cada Estado, la satisfacción de los derechos económicos, sociales y culturales, indispensables a su dignidad y al libre desarrollo de su personalidad ${ }^{34}$.

En semejante tenor, el artículo 9o del Protocolo de San Salvador, adicional a la Convención Americana sobre Derechos Humanos en materia de derechos económicos, sociales y culturales, reafirma la concepción de la seguridad social como derecho humano, universal y progresivo, señalando que

1. Toda persona tiene derecho a la seguridad social que la proteja contra las consecuencias de la vejez y de la incapacidad que la imposibilite física o mentalmente para obtener los medios para llevar una vida digna y decorosa. En caso de muerte del beneficiario, las prestaciones de seguridad

\footnotetext{
${ }^{33}$ Carpizo, Jorge, "Una clasificación de los derechos de la justicia social”, en Ferrer MacGregor, Eduardo et. al.(coord.), Construcción y Papel de los Derechos Sociales Fundamentales, 1a. ed., México, UNAM, Instituto de Investigaciones Jurídicas, 2011, p. 419, consultado en https://archivos.juridicas.unam.mx/wrww/bjv/libros/7/3063/17.pdf, el 18 de agosto de 2018.

${ }^{34}$ Declaración Universal de Derechos Humanos, op. cit., nota 26.
} 
social serán aplicadas a sus dependientes.

2. Cuando se trate de personas que se encuentran trabajando, el derecho a la seguridad social cubrirá al menos la atención médica y el subsidio o jubilación en casos de accidentes de trabajo o de enfermedad profesional $\mathrm{y}$, cuando se trate de mujeres, licencia retribuida por maternidad antes y después del parto ${ }^{35}$.

De las anteriores consideraciones se advierte que los tratados, convenios y demás instrumentos internacionales reafirman la concepción de la seguridad social como un derecho universal, de toda persona; pero establecen un régimen especial para aquellos que, al ser sujetos de una relación laboral, se encuentran expuestos en mayor medida a los infortunios del trabajo y que, en consecuencia, requieren de una protección especial, constituida por los seguros de enfermedades profesionales, accidentes de trabajo, invalidez y desempleo.

No obstante, como se estableció anteriormente, en tratándose del sistema de seguridad social mexicano, la universalidad se ha convertido en una tendencia, más que en un principio característico y fundamental de dicho derecho humano; a grado tal que el texto del artículo 123 constitucional y de las legislaciones secundarias que regulan la materia, parece invertir las consideraciones de los tratados internacionales, concibiendo la seguridad social como un derecho eminentemente laboral que, en todo caso, es susceptible de extenderse en favor de los campesinos, no asalariados y demás sectores sociales, a través de la incorporación voluntaria. Resultando ilustrativas las palabras de Ávila Salcedo, quien al respecto advierte que:

Técnicamente, los sistemas de seguro social tienen como destinatarios a los trabajadores dependientes. Sin embargo, la tendencia jurídica ha sido la expansión a otros sectores, a otros grupos inicialmente no considerados como beneficiarios. De esta manera se va disipando la idea de centralizar en el trabajador dependiente la acción de protección para

\footnotetext{
${ }^{35}$ Protocolo adicional a la Convención Americana sobre Derechos Humanos en materia de derechos económicos, sociales y culturales "Protocolo de San Salvador", op. cit., nota 29.
} 
transitar a un sistema que incluya a personas con otra calidad, por ejemplo y entre otras posibilidades: inscribir al cónyuge, al compañero o compañera permanente, a los hijos del trabajador o personas que sin tener en su familia trabajadores dependientes, son sujetos de las prestaciones asistenciales o económicas, según corresponda ${ }^{36}$.

No debe perderse de vista que, en atención a que la seguridad social constituye un derecho humano reconocido -primordialmente- por la fracción XXIX del apartado A del artículo 123 constitucional y los múltiples instrumentos internacionales a que se ha hecho referencia, a partir de la reforma a la Constitución Mexicana publicada en el Diario Oficial de la Federación del 10 de junio de 2011, el segundo párrafo del artículo $1^{\circ}$ constituye el fundamento a razón del cual los referidos campesinos, no asalariados y demás sectores sociales que no tiene acceso al sistema de seguridad social, podrían exigir del Estado la vigencia plena de dicho derecho, sin el requerimiento de afiliación voluntaria al régimen previsto por la legislación secundaria.

Lo anterior es así toda vez que, si bien el referido artículo dispone que las normas relativas a los derechos humanos deberán de interpretarse de conformidad con lo dispuesto por la propia Constitución, lo que en principio nos remitiría a las restricciones dispuestas por la fracción XXIX del apartado A del artículo 123 y las fracciones XI y XIII del apartado B del mismo precepto, lo cierto es que el texto reformado otorga igual jerarquía a los tratados internacionales en materia de derechos humanos, favoreciendo en todo momento a las personas la protección más amplia.

De manera que si instrumentos internacionales tales como la Declaración Universal de Derechos Humanos y el Protocolo de San Salvador reconocen en favor de toda persona el derecho a la seguridad social, que la proteja contra las eventualidades que le imposibiliten para obtener los medios para llevar una vida digna y decorosa, sin restringirlo de modo alguno o condicionarlo a la satisfacción de

\footnotetext{
${ }^{36}$ Ávila Salcedo, Luis F., op. cit., nota 4, p. 27.
} 
mayores requisitos, es inconcuso que de conformidad con lo dispuesto por el artículo $1^{\circ}$ de la Constitución Política de los Estados Unidos Mexicanos y la interpretación pro homine, no podrá negarse a ninguna persona el acceso a las prestaciones que prevén las legislaciones de seguridad social, bajo el argumento de la exigencia de afiliación, ya sea voluntaria u obligatoria.

Máxime si se considera que el Protocolo de San Salvador establece la prohibición expresa de restringir la protección de los llamados derechos económicos, sociales y culturales en favor de la realización de los diversos derechos civiles y políticos, y viceversa:

Considerando la estrecha relación que existe entre la vigencia de los derechos económicos, sociales y culturales y la de los derechos civiles y políticos, por cuanto las diferentes categorías de derechos constituyen un todo indisoluble que encuentra su base en el reconocimiento de la dignidad de la persona humana, por lo cual exigen una tutela y promoción permanente con el objeto de lograr su vigencia plena, sin que jamás pueda justificarse la violación de unos en aras de la realización de otros ${ }^{37}$.

Por tanto, quien estas líneas escribe comparte la concepción del derecho a la seguridad social sostenida en la octogésima novena reunión de la Conferencia Internacional del Trabajo, celebrada en el año 2001, en la cual se reafirmó la trascendencia de aquél como un derecho fundamental, a saber:

La seguridad social es muy importante para el bienestar de los trabajadores, de sus familias y de toda la sociedad. Es un derecho humano fundamental y un instrumento esencial para crear cohesión social, y de ese modo contribuye a garantizar la paz social y la integración social. Forma parte indispensable de la política social de los gobiernos y es una herramienta importante para evitar y aliviar la pobreza. A través de la solidaridad nacional y la distribución justa de la carga, puede contribuir a la dignidad humana, a la equidad y a la justicia social. También es importante para la integración política, la participación de los ciudadanos y

\footnotetext{
${ }^{37}$ Protocolo adicional a la Convención Americana sobre Derechos Humanos en materia de derechos económicos, sociales y culturales "Protocolo de San Salvador", op. cit., nota 29.
} 
el desarrollo de la democracia ${ }^{38}$.

IV. DUPLICIDAD EN EL ASEGURAMIENTO Y EL PROBLEMA DEL FINANCIAMIENTO

Ya desde 1941, al evaluar la eficiencia del seguro social inglés, sir William Beveridge destacó la falta de coordinación administrativa entre los servicios existentes, como una de las deficiencias de aquél ${ }^{39}$. Asimismo, y como se apuntó con anterioridad, la ausencia de unidad en la administración y gestión de la seguridad social constituye uno de los grandes problemas del sistema mexicano.

En efecto, según lo dispuesto por el artículo 123 constitucional, en la fracción XXIX del apartado A y las fracciones XI y XIII del apartado B, la realización de la seguridad social -esto es, la administración de los seguros, prerrogativas y servicios respectivos- está a cargo de tres organismos públicos descentralizados, con personalidad jurídica y patrimonio propios, que disponen cada uno de una ley reglamentaria que contiene y regula las prestaciones correspondientes a cada régimen de seguridad social: el Instituto Mexicano del Seguro Social (IMSS), el Instituto de Seguridad y Servicios Sociales de los Trabajadores del Estado (ISSSTE) y el Instituto de Seguridad Social para las Fuerzas Armadas Mexicanas (ISSFAM).

Determinación que por sí sola contraviene el principio jurídico de unidad, que por definición y junto con la universalidad, integridad, solidaridad, subsidiaridad e internacionalidad, determina los fines y propósitos de la seguridad social. En pocas palabras, por unidad debe entenderse "la conveniencia de la gestión unitaria del sistema de seguridad social” ${ }^{40}$, con el objeto de evitar el dispendio de recursos y el retraso en la prestación de los servicios correspondientes.

\footnotetext{
${ }^{38}$ Cázares García, Gustavo, op. cit., nota 9, p. 94.

${ }^{39}$ Sánchez - Castañeda, Alfredo, op.cit., nota 1, p. 10.

${ }^{40}$ Carrillo Prieto, Ignacio, Derecho de la seguridad social, 1a. ed., México, MacGraw-Hill - UNAM, Instituto de Investigaciones Jurídicas, 1997, colección Panorama del Derecho Mexicano, p. 12, consultado en https://archivos.juridicas.unam.mx/wrw/bjo/libros/4/1928/3.pdf, el 20 de agosto de 2018.
} 
Esta multiplicidad de instituciones primariamente responsables de la prestación de los servicios públicos de seguridad social, ha derivado en otra importante deficiencia: la duplicidad en el aseguramiento que, en contraste con la falta de universalidad, debe entenderse como la doble o hasta triple cobertura de un mismo individuo respecto de las diversas instituciones encargadas de la administración y organización de los seguros sociales.

Esto es así ya que las diversas legislaciones en materia de seguridad social prevén, en principio de cuentas, múltiples y muy diversas prestaciones para tres grupos sociales disímiles entre sí: los trabajadores protegidos por el apartado A del artículo 123 de la Constitución y los campesinos, no asalariados y otros sectores sociales y sus familias, en tratándose de la Ley del Seguro Social; los trabajadores al servicio del Estado, por lo que respecta a la Ley del ISSSTE, y los miembros del Ejército, de la Fuerza Aérea y de la Armada de México, en activo o en situación de retiro, y sus familiares en línea directa, por cuanto hace a la Ley del Instituto de Seguridad Social para las Fuerzas Armadas Mexicanas. Lo anterior, sin perjuicio de los argumentos opuestos en precedentes párrafos, respecto de la utopía de la universalidad y los campesinos, no asalariados y demás sectores sociales a que hace referencia la fracción XXIX del apartado A del artículo 123 constitucional, quienes sólo podrán acceder voluntariamente, a través de convenio celebrado con el Instituto y el respectivo pago de una cuota anual, a las prestaciones del régimen obligatorio contemplado por la Ley del Seguro Social.

En segundo término, ninguna disposición impide que un mismo individuo sea sujeto de la protección de dos o más regímenes de seguridad social a la vez y que, como tal, tenga acceso de manera conjunta a las prestaciones en dinero -subsidios, pensiones, indemnizaciones, gastos funerarios, ayuda de matrimonio- y en especie asistencia médica, quirúrgica, farmacéutica, hospitalaria- propias de cada uno de éstos. Situación que, como se argumentó anteriormente, provoca que el individuo que ha cotizado para dos o más institu- 
ciones de seguridad social -verbi gratia, para ISSSTE e IMSS- pueda disfrutar, simultáneamente, de dos o más pensiones, en detrimento de las finanzas que soportan el sistema de seguridad social.

Es decir que, en oposición al fracaso de la universalidad que se traduce en el acceso restringido y limitado a los servicios públicos y prestaciones que conforman los seguros sociales, nada impide que aquel trabajador al servicio del Estado, que también cotizó en el régimen obligatorio del seguro social (IMSS), disfrute a la par de una pensión por riesgo de trabajo, en términos de la fracción II del artículo 62 de la Ley del ISSSTE y de una pensión de invalidez, conforme a los artículos 119 y 120, fracción II, de la vigente Ley del Seguro Social; pudiendo, además, obtener una tercera pensión, ahora por viudez o por causa de muerte, en atención a su calidad de beneficiario o causahabiente, según lo dispuesto por los artículos 64 , fracción II, y 127, fracción I, de esta última legislación, o los diversos artículos 67, 68, fracción I, y 129 de aquella.

Respecto de este último supuesto, la Segunda Sala de la Suprema Corte de Justicia de la Nación ha determinado que el artículo 12, párrafo segundo, del Reglamento para el Otorgamiento de Pensiones de los Trabajadores Sujetos al Régimen del Artículo Décimo Transitorio del Decreto por el que se expide la Ley del Instituto de Seguridad y Servicios Sociales de los Trabajadores del Estado, viola el derecho a la seguridad social previsto en el artículo 123, apartado B, fracción XI, inciso a), de la Constitución Política, al restringir injustificadamente el disfrute simultáneo de una pensión por viudez y otra por jubilación, cuando su importe conjunto rebase los diez salarios mínimos ${ }^{41}$.

El Alto Tribunal sostuvo dicho criterio bajo el argumento de que las pensiones por viudez y por jubilación otorgadas al amparo de la Ley del Instituto de Seguridad y Servicios Sociales de los Trabajadores del Estado tienen orígenes diferentes, cubren distintos riesgos y guardan plena autonomía financiera:

${ }^{41}$ Tesis: I.1o.A. J/14 (10a.), Gaceta del Semanario fudicial de la Federación, Décima Época, Libro 40, Tomo IV, marzo de 2017, p. 2505. 
1. Dichas pensiones tienen orígenes distintos, pues la primera surge con la muerte del trabajador y la segunda se genera día a día con motivo de los servicios prestados por el trabajador; 2. Cubren riesgos diferentes, toda vez que la pensión por viudez protege la seguridad y el bienestar de la familia ante el riesgo de la muerte del trabajador y la pensión por jubilación protege su dignidad en la etapa de retiro; y, 3. Tienen autonomía financiera, ya que la pensión por viudez se genera con las aportaciones hechas por el trabajador o pensionado fallecido y la pensión por jubilación se genera con las aportaciones hechas por el trabajador o pensionado, motivo por el cual no se pone en riesgo la viabilidad financiera de las pensiones conjuntas ${ }^{42}$.

En cambio, no existe pronunciamiento alguno emitido por la $\mathrm{Su}-$ prema Corte de Justicia de la Nación respecto del disfrute conjunto de una pensión por incapacidad permanente -derivada de un riesgo profesional-, sea total o parcial, y una pensión por invalidez, en términos de lo dispuesto por las diversas legislaciones del ISSSTE y del Seguro Social, respectivamente. Prerrogativas que, a pesar de tener orígenes distintos y autonomía financiera, han llegado a confundirse ante la ausencia de unificación normativa sobre la materia; como se advierte de la sentencia dictada por el Cuarto Tribunal Colegiado de Circuito del Centro Auxiliar de la Tercera Región, con residencia en Guadalajara, Jalisco, el 10 de marzo de 2016 en autos del amparo directo laboral 66/2016 de su índice:

Sin embargo, este órgano colegiado estima insuficientes las razones que dio la responsable para condenar al Instituto quejoso al reconocimiento del estado de invalidez de la actora y al otorgamiento del dictamen de invalidez definitivo, dado que, de manera dogmática, refirió que si bien era cierto dichos padecimientos para el * [Instituto de Seguridad y Servicios Sociales de los Trabajadores del Estado] fueron calificados como enfermedad profesional, también lo era que para el * [Instituto Mexicano del Seguro Sociall, debían ser considerados como enfermedad general, sin

${ }^{42}$ Tesis aislada 2a. CXII/2014 (10a.), Gaceta del Semanario Fudicial de la Federación, Décima Época, Libro 12, Tomo I, noviembre de 2014, p. 1191. 
que precisara, fundada y motivadamente, por qué razón ese accidente de trabajo que tuvo la actora en el *** * [Instituto de Salud en el Estado de Aguascalientes], repercutió en su estado de salud a grado tal que, aun cuando su origen fue de carácter profesional, afectó su salud produciéndole la invalidez que se indicó ${ }^{43}$.

Es cierto que las pensiones referidas no comparten el mismo financiamiento -como sucede también en tratándose del resto de contingencias: cesantía en edad avanzada, vejez y muerte-, pues las cuotas obrero patronales corren a cargo de diverso patrón; sin embargo, sí existe una doble aportación estatal o cuota social a cargo del Gobierno Federal respecto de un mismo individuo.

Situación que no sólo contrasta con la omisión del Estado de proporcionar seguridad social a aquellos que no se ubican en los supuestos específicamente previstos por el artículo 123 constitucional, en la fracción XXIX del apartado A y las fracciones XI y XIII del apartado B; sino que, además, vulnera el principio de solidaridad, que consiste en la distribución equitativa de las cargas económicas que genera el otorgamiento de las prestaciones de seguridad social, de manera que quien perciba más ingreso realice mayores aportaciones, en beneficio general de la colectividad y "sin que necesariamente dicho aporte quede supeditado a la posibilidad de obtener un beneficio o prestación proporcional" ${ }^{44}$.

Por tanto, es de concluirse que la seguridad social presupone unidad orgánica, como uno de sus principios jurídicos fundamentales, exigiendo "unificación en materia normativa, administrativa y financiera para así evitar autonomía de acciones, dispersidad (sic) de recursos e incremento de costos" ${ }^{45}$ e impidiendo "la duplicidad de entidades que aseguren una misma contingencia, para evitar la pluralidad en la gestión y procurar la inmediatez en el servicio" ${ }^{46}$.

\footnotetext{
${ }^{43}$ Amparo directo 66/2016. Instituto Mexicano del Seguro Social. 10 de marzo de 2016. Unanimidad de votos. Ponente: Juan Manuel Rochín Guevara. Secretaria: Michelle Stephanie Serrano González.

${ }^{44}$ Ávila Salcedo, Luis F., op. cit., nota 4, p. 31.

${ }^{45}$ Cázares García, Gustavo, op. cit., nota 9, p. 96.

${ }^{46}$ Ávila Salcedo, Luis F., op. cit., nota 4, p. 30.
} 


\section{PROPUESTA DE SOLUCIÓN: EL RETORNO AL PLAN BEVERIDGE Y LA CREACIÓN DE UN SISTEMA ÚNICO DE PENSIONES}

De lo expuesto se advierte que en nuestro país, la seguridad social es concebida como un derecho obrero, garantizado por el artículo 123 de la Constitución Política de los Estados Unidos Mexicanos, en la fracción XXIX del apartado A y las fracciones XI y XIII del apartado B; situación que per sé genera una delimitación de su cobertura -así como de su financiamiento-, constriñéndose a la población económicamente activa. Asimismo, la fragmentación del sistema de seguridad social mexicano, entendiéndose por tal la multiplicidad de instituciones primariamente responsables de la prestación de estos servicios -IMSS, ISSSTE e ISSFAM-, provoca la duplicidad en el aseguramiento, lo que se traduce en un indebido detrimento económico en las escasas reservas que hoy en día apenas alcanzan para sostenerlo.

En tal virtud, resulta urgente la solución de tal problemática mediante la reestructuración legislativa, económica y financiera del derecho mexicano a la seguridad social, sin soslayar la universalidad y unidad como principios jurídicos del mismo. Temática que ha sido abordada en el presente análisis, con el objeto de determinar un diagnóstico preciso de las consecuencias generadas y aportar soluciones viables, concebidas a partir de un enfoque eminentemente constitucional.

Al 31 de julio de 2018, el Instituto Mexicano del Seguro Social tiene registrados $19^{\prime} 949,244$ puestos de trabajo ${ }^{47}$; lo cual implica que la cifra de derechohabientes protegidos por aquel es incluso mayor, si se considera a las familias de los trabajadores dependientes asegurados y a aquellos campesinos, no asalariados y demás sectores sociales que se encuentran voluntariamente afiliados a dicho régi-

${ }^{47}$ Instituto Mexicano del Seguro Social, consultado en http://wrww.imss.gob.mx/ el 21 de agosto de 2018. 
men de seguridad social. No obstante, es preciso reiterar que dicha cobertura no comprende a la población en general, como dispone el artículo 123 de la Constitución Política de los Estados Unidos Mexicanos.

Dado su esquema de función y financiamiento -el asalariado recibe una contraprestación a cambio de la aportación que el Estado, el patrón y el propio trabajador realizan-, el sistema de seguridad mexicano se encuentra organizado con base en el modelo alemán desarrollado por Bismarck ${ }^{48}$ a partir de 1883. No obstante, "afrontar los costos que demanda la seguridad social requiere imaginar modelos que contemplen formas varias o alternativas diferentes para allegar los recursos necesarios a la seguridad social” ${ }^{49}$; por tanto, la propuesta principal consiste en la reestructuración del sistema mexicano de seguridad social, con base en el diverso modelo inglés, instaurado hasta 1942.

En efecto, según se señaló con anterioridad, el llamado Plan Beveridge se caracterizó por cimentarse en los principios de universalidad y solidaridad; esto es, procuró garantizar una protección mínima para la sociedad en general -servicios médicos, una pensión por vejez y gastos de entierro- y no sólo para la población económicamente activa, estableciendo una tasa de contribución fija a razón de la cual quien percibiera mayores ingresos realizaría mayores aportaciones:

El plan de seguridad social se distinguió principalmente por pretender abarcar a todas las personas y no solo a quienes trabajan para patrones. La cobertura del sistema no sería igual para aquellos trabajadores independientes, o quienes se encuentran desempleados, más sí se les garantizaría a todos protección contra la vejez, gastos de defunción y asistencia médica. Su campo de cobertura comprendía los seguros de enfermedad, desocupación, vejez, muerte y riesgos de trabajo.

Su sistema financiero se integraría por las contribuciones hechas por el Estado, los trabajadores y los patrones ${ }^{50}$.

\footnotetext{
${ }^{48}$ Sánchez - Castañeda, Alfredo, op.cit., nota 1, p. 25.

${ }^{49}$ Ibidem, p. 132.

${ }^{50}$ Cázares García, Gustavo, op. cit., nota 9, p. 21.
} 
Se propone la reestructuración del sistema de seguridad social, en lo referente a las pensiones y prestaciones de carácter económico, a razón de un sólo organismo público descentralizado, con personalidad jurídica y patrimonio propios; buscando la unificación de los supuestos legales para la procedencia de tales beneficios, su administración y financiamiento, mediante la implementación de los seis principios fundamentales que dieran contenido al Social Insurance and Allied Service:

1. Tasa fija de beneficio de subsistencia. Previsión de una tasa fija de beneficio de seguro, sin tener en cuenta el total de los ingresos, interrumpidos por la desocupación o la incapacidad, o terminados por el retiro. La única excepción consiste en la incapacidad prolongada como consecuencia de una enfermedad o accidente industrial. La tasa fija es igual para las principales maneras de cesación de ingresos: desocupación, incapacidad, retiro; para maternidad y viudez hay un beneficio provisorio de tasa más elevada.

2. Tasa fija de contribución. La contribución obligatoria requerida de cada asegurado o de su empleador, es una tasa fija, sin tener en cuenta sus recursos. Se paga la misma contribución por la misma seguridad. Los que disponen de mayores recursos pagarán más a la Tesorería Nacional, y en ese sentido por su conducto, a la cuota estatal del fondo de seguridad social. La única excepción consiste en el costo especial de los beneficios y de las pensiones por incapacidad industrial, en las ocupaciones de alto riesgo, mediante un tributo que pagarán los empleadores, en proporción al riesgo y a la lista de paga.

3. Unificación de la responsabilidad administrativa. Unificación de la responsabilidad administrativa en interés de la eficiencia y economía, para cada persona una única contribución semanal vinculada a los beneficios. Una Oficina de Seguridad en cada localidad para atender toda clase de reclamaciones. Todas las contribuciones se depositan en un único Fondo de Seguro Social. Todos los beneficios y pagos de seguro son atendidos con dicho fondo.

4. Adecuación de beneficios en cantidad y en tiempo. Se parte del principio que la tasa fija de beneficio propuesta es suficiente, sin acudir 
a otros recursos, para promover el ingreso mínimo necesario para la subsistencia, con todos los casos normales. Los beneficios son adecuados en tiempo; salvo contingencias temporales, continuarán indefinidamente, sin investigación de recursos, en tanto subsista la necesidad.

5. Extensión o alcance del Seguro. Amplitud del ámbito de aplicación tanto con respecto a las personas cubiertas como a los riesgos que debían protegerse (cobertura vertical y horizontal).

6. Clasificación de las personas. La seguridad social debía aplicarse teniendo en cuenta los diferentes modos de vida de los asegurados ${ }^{51}$.

De las anteriores consideraciones, es digno de destacar el establecimiento de tasas fijas tanto para el beneficio de seguro como para la contribución; de manera que no sólo se prevé la universalidad en tratándose de la cobertura de los servicios de seguridad social, sino también respecto al financiamiento del sistema. Lo anterior en virtud de que, al gravarse un porcentaje determinado del ingreso general y no sólo del salario, se extiende la responsabilidad del financiamiento del sistema de seguridad social a los trabajadores independientes, comerciantes, no asalariados y demás sectores sociales; quienes gozarán de un beneficio mínimo garantizado semejante al que en su caso reciban los trabajadores dependientes, incluyéndose en dicha protección a los patrones, quienes a pesar de contribuir prioritariamente al mantenimiento y sustentabilidad del sistema de seguridad social actual, sólo pueden acceder a las prestaciones relativas mediante su incorporación voluntaria.

Asimismo, tales medidas también promueven el principio de solidaridad, pues al gravarse un porcentaje determinado de los ingresos, aquellos que perciban más ganancias realizarán mayores aportaciones en beneficio general de la colectividad; sosteniendo con su contribución el sistema de seguridad social, pero gozando también de las prestaciones que éste comprenda, con base en la clasificación que a su estilo de vida corresponda.

\footnotetext{
${ }^{51}$ Sánchez - Castañeda, Alfredo, op.cit., nota 1, pp. 11, 12.
} 
Finalmente, el modelo propuesto representa de manera precisa el principio de unidad, pues pugna por la administración única y centralizada de las prestaciones de carácter económico que a la seguridad social corresponden, tales como subsidios, pensiones, indemnizaciones, gastos funerarios, ayuda de matrimonio, etc.; mediante la creación de un organismo público descentralizado, con personalidad jurídica y patrimonio propios, encargado de la gestión pública de los recursos y el manejo exclusivo de un fondo de seguro social. Supuesto sugerido, incluso, por Sánchez - Castañeda, quien refiere que "se debe considerar la creación de un sistema nacional de pensiones que contemple el establecimiento de un Instituto Nacional de Pensiones, el cual se encargaría de centralizar la organización y administración de las pensiones, a partir de una gestión pública que privilegie el interés público y no el lucro privado" ${ }^{52}$.

Por tanto, de concretarse la propuesta referida en las reformas constitucionales y legales pertinentes, se lograrían erradicar los principales vicios de que adolece en la actualidad el sistema de seguridad social mexicano: la falta de universalidad en su cobertura y la multiplicidad de instituciones primariamente responsables de la prestación de los servicios públicos correspondientes; con lo cual se alcanzaría la plena efectividad del derecho humano a la seguridad social consagrado en los artículos 123 de la Constitución Política de los Estados Unidos Mexicanos, 22 de la Declaración Universal de Derechos Humanos y $9^{\circ}$ del Protocolo de San Salvador, como intrínseco a la persona humana en general y no sólo en atención a su condición de desventaja.

\section{FUENTES}

1. Bibliografia

ÁVILA SALCEDO, Luis F., La seguridad social y el Instituto Mexicano del Seguro Social, 1a. ed., México, Editorial Porrúa, 2007, pp. 187.

\footnotetext{
${ }^{52}$ Ibidem, p. 174.
} 
BURGOA, Ignacio, Las garantías individuales, 41a. ed., México, Editorial Porrúa, 2009 , pp. 814.

CAPÓN FILAS, Rodolfo y Giorlandini, Eduardo, Diccionario de Derecho Social. Derecho del trabajo y la seguridad social, 1a. ed., Argentina, Rubinzal y Culzoni Editores, 1987, pp. 534, consultado en https://archivos.juridicas.unam. $m x / w r e w / b j o / l i b r o s / 3 / 1412 / 10 . p d f$, el 08 de agosto de 2018 .

CARPIZO, Jorge, "Una clasificación de los derechos de la justicia social”, en Ferrer MacGregor, Eduardo et. al.(coord.), Construcción y Papel de los Derechos Sociales Fundamentales, 1a. ed., México, UNAM, Instituto de Investigaciones Jurídicas, 2011, pp. 464, consultado en https://archivos.juridicas. unam.mx/wrew/bjo/libros/7/3063/17.pdf, el 18 de agosto de 2018.

CARRILLO PRIETO, Ignacio, Derecho de la seguridad social, 1a. ed., México, MacGraw-Hill - UNAM, Instituto de Investigaciones Jurídicas, 1997, colección Panorama del Derecho Mexicano, pp. 53, consultado en https://archivos.juridicas.unam.mx/wrere/bjo/libros/4/1928/3.pdf, el 20 de agosto de 2018.

CÁZARES GARCÍA, Gustavo, Derecho de la seguridad social. Historia, doctrina y jurisprudencia, 3a. ed., México, Editorial Porrúa, 2014, pp. 694.

Constitución Política de los Estados Unidos Mexicanos, que reforma la de 5 de febrero de 1857, consultado en https://wrere.scjn.gob.mx/sites/default/files/cpeum/ documento/2017-03/CPEUM-123.pdf, el 10 de agosto de 2018.

Declaración Universal de Derechos Humanos, consultado en https://wrere.ohchrorg/ EN/UDHR/Documents/UDHR_Translations/spn.pdf, el 15 de agosto de 2018.

DE LA CUEVA, Mario, El nuevo derecho mexicano del trabajo, 7a. ed., t. II, México, Editorial Porrúa, 1981, pp. 648.

LÓPEZ RUÍZ, Miguel (editor), Diccionario jurídico sobre seguridad social, 1a. ed., México, ISSSTE - IMSS - UNAM, Instituto de Investigaciones Jurídicas, 1994, pp. 506, consultado en https://archivos.juridicas.unam.mx/wrww/ bjo/libros/2/736/4.pdf, el 08 de agosto de 2018.

Organización Internacional del Trabajo, consultado en http://wrerceilo.org/global/about-the-ilo/history/lang--es/index.htm, el 10 de agosto de 2018. 
Pacto Internacional de Derechos Económicos, Sociales y Culturales, consultado en https://wrere.ohchr.org/sp/professionalinterest/pages/cescraspx, el 15 de agosto de 2018.

Protocolo adicional a la Convención Americana sobre Derechos Humanos en materia de derechos económicos, sociales y culturales "Protocolo de San Salvador", consultado en http://legislacion.scjn.gob.mx/Buscador/Paginas/wefOrdenamientoDetalle. aspx:q=PlOrqrSvLTzAsquzQ7fUky 4kZb76bUIVN1 T2hXjH6GTCSSSSNoFeTrwOgvEINFjM8, el 15 de agosto de 2018.

RODRÍGUEZ Y RODRÍGUEZ, Jesús, "Derechos Sociales”, Diccionario furídico Mexicano, 1a. ed., México, UNAM, Instituto de Investigaciones Jurídicas, 1983, t. III, pp. 359, https://archivos.juridicas.unam.mx/wrww/bjo/ libros/3/1170/9.pdf.

SÁNCHEZ - CASTANEDA, Alfredo, La seguridady la protección social en México: su necesaria reorganización, 1a. ed., México, UNAM, Instituto de Investigaciones Jurídicas, 2012, pp. 198.

, "La reformulación de los paradigmas: la reforma a la seguridad social y la creación del Instituto Mexicano de Protección Social”, en Mendizábal Bermúdez, Gabriela et. al. (coord.), Condiciones de Trabajo y Seguridad Social, 1a. ed., México, UNAM, Instituto de Investigaciones Jurídicas, consultado en 2012, pp. 363, https://archivos.juridicas.unam.mx/werew/bjo/ libros/7/3142/2.pdf, el 12 de agosto de 2018. 